\title{
Bio-additives for $\mathrm{Cl}$ engines from one-pot alcoholysis reaction of lignocellulosic biomass: an experimental activity
}

\author{
Anna Maria Raspolli Galletti ${ }^{1}$, Gianluca Caposciutti ${ }^{2}$, Gianluca Pasini $^{2}$, Marco Antonelli $^{2}$, Stefano Frigo ${ }^{2, *}$. \\ ${ }^{1}$ Università di Pisa, Dipartimento di Chimica e Chimica Industriale, Via Giuseppe Moruzzi, 56124 Pisa. \\ ${ }^{2}$ Università di Pisa, Dipartimento di Ingegneria dell'Energia, dei Sistemi, del Territorio e delle Costruzioni, Largo Lucio Lazzarino, \\ 56126 Pisa.
}

\begin{abstract}
In the recent years the progressive decrease in fossil petroleum resources and gradual deprivation of the environment have attracted increasing interest towards the use of biomass as renewable carbon source for the production of chemicals and transportation fuels. In particular, lignocellulosic biomass represents an abundant and inexpensive renewable resource with high carbon sequestration ability and non-polluting.

In this paper, the valorisation of mixtures made of n-butanol (n-BuOH), butyl levulinate (BL) and dibutyl ether (DBE), in different percentages, as additive fuel for compression ignition (CI) internal combustion engine (ICE) was studied. These mixtures can be directly obtained from the catalytic alcoholysis reaction of the cellulosic fraction of raw and pre-treated lignocellulosic biomasses. Moreover, the possibility to recycle and reutilize the excess alcohol (n-Butanol), during the catalytic alcoholysis reaction, has been considered since it represents an opportunity to reduce the overall costs of the process. Therefore, a blend constituted only by BL and DBE has been also tested. The model mixtures were prepared by using commercial reactants, characterized by compositions analogous to those of the reaction mixtures. These model mixtures were tested as blend with Diesel fuel in a CI-ICE with the measurement of pollutant emission and performance. Results have been compared with those obtained fuelling the engine with a commercial Diesel fuel. As a whole, tests results have evidenced the potentiality of these novel blending mixtures to reduce the emissions of particulate without any significant increase in the other pollutants and negligible changes in engine power and efficiency.
\end{abstract}

\section{Introduction}

In recent years, renewable fuel additives have been attracting more and more attention, especially in Europe, due to the new regulations concerning the improvement of renewables in fuel composition.

In this work, the valorisation of mixtures made of n-butanol (n-BuOH), butyl levulinate (BL) and dibutyl ether (DBE), in different percentages, as additive fuel for compression ignition (CI) internal combustion engine (ICE) was studied. These mixtures can be directly obtained from the acid-catalysed alcoholysis reaction of the cellulosic fraction of raw and pre-treated lignocellulosic biomasses. The detailed description of the chemical process adopted to obtain the aforementioned components has been the subject of a previous work [1, 2]. Nevertheless, it is important to underline that the single step alcoholysis reaction of lignocellulosic biomasses, using n-Butanol (n-BuOH) and diluted inorganic acid as homogeneous catalyst, produces BL from cellulose and $\mathrm{DBE}$ deriving from $\mathrm{n}-\mathrm{BuOH}$ etherification. The mixture obtained from the reaction is mainly composed by unreacted n-BuOH, DBE and BL.

Large amount of literature, especially for BL synthesis, results available [3, 4, 5]. The one-pot approach starting from cheap biomasses is certainly more interesting than a two-step process due to cost reduction associated with the purification and isolation of the intermediates. Fast-growing and not edible lignocellulosic biomass represents a sustainable and ideal feedstock to produce $2^{\text {nd }}$ generation bio-fuel [6]. In this context, the fractionation and valorisation of each component (i.e. cellulose, hemicellulose and lignin) can be used to develop completely suitable processes in an integrated biorefinery outlook. Within levulinic acid esters, BL represents an ideal bio-additives for Diesel fuel [7]. As a matter of fact, its high boiling point makes difficult its application as gasoline bio additive [8]. However, Janssen et al. [3] showed that operations with pure BL cannot be realized in CI-ICE due to its reduced cetane number (CN). Therefore, they tested BL in blend with $n$-tedradecane and $70 / 30 \mathrm{BL} / n$-tedradecane volumetric ratio, obtaining a notable soot reduction in comparison with Diesel. A reduction of particulate emission was also reported by Christensen et al. [7], with a blend of BL/Diesel 20/80 volumetric ratio with certification ULSD in presence of suitable cetane enhancer (e.g. 2-ethylhexyl nitrate).

*Corresponding author: s.frigo@,ing.unipi.it 
Unlike BL, DBE has a high cetane number and for this reason it has already been tested in blend with Diesel. For instance, Zubel et al. [4] reported that the addition of DBE to diesel fuel led to an increase of soot emission at low loads and, by contrast, a decrease at high loads. Moreover, Gao et al. [5] carried out experimental and chemical kinetics studies to investigate the effects of DBE addition to a biodiesel surrogate (methyl decanoate) on soot formation in laminar coflow diffusion flames, showing that DBE is effective in terms of suppressing soot formation and reducing particle emission. Unreacted $n$-butanol is also present in the final mixture post reaction. Rakopoulos et al. reported that increasing blend Diesel-butanol $\left(8,16,24 \%\right.$ by volume) led to a significant decrease in the $\mathrm{NO}_{\mathrm{x}}$ and $\mathrm{CO}$ in comparison with neat Diesel [9].

On the contrary, the utilisation of high amount of $\mathrm{n}-\mathrm{BuOH}$ in Diesel engine is challenging, owing to its low cetane number, even if it was extensively tested in the past years as green additive fuel and recently there is a renewed interest into this application, as testified by several experimental and review articles [10-19]. It is not the scope of the present work to review all the scientific literature regarding the utilisation of higher alcohol biofuels in Diesel engines, but it is worthwhile to recall that, as a whole, the utilisation of blends composed by n-Butanol and Diesel fuel (with n-Butanol up to $35 \%$ by vol.) reduce smoke emissions, with their fuel-borne oxygen, and enhance air/fuel mixing by offering long ignition delay, hence enabling a clean and efficient combustion in compression-ignition engines.

The one-pot acid catalysed alcoholysis reaction, considered in the present application, is influenced by three main parameters: temperature, time and catalyst loading. Taking into account the versatility of this type of reaction, composition of the final mixture can be selected by properly choosing the reaction conditions. Therefore, two ternary mixtures $n$ $\mathrm{BuOH} / \mathrm{BL} / \mathrm{DBE}$ were tested as blend with Diesel fuel $(10$ and $20 \% \mathrm{v} / \mathrm{v})$ in a CI engine. Moreover, the possibility to fully recycle and reutilize the excess alcohol (n-Butanol) has been also considered, since it represents an opportunity to reduce the overall costs of the process (in line with the principle of the circular economy), therefore a third mixture constituted only by BL and DBE was utilized for the engine tests. The feasible separation and recovery of the solvent/excess reactant, $n$-Butanol, has already been reported for similar mixtures [20]. It must be also considered that BL, which can be obtained from the cellulosic fraction of not edible lignocellulosic biomass [21,22], represents a promising advanced biofuel and, in the different types of blends containing the main products obtainable from the one-pot alcoholysis of lignocellulosic biomasses, it constitutes the effective renewable component. Last but not least, in a green prospective, also n-BuOH can be obtained from renewables, adopting ABE process or the promising Guerbet condensation of bioethanol [23].

The present experimental study represents a further insight into the utilization of oxygenated biofuels in Diesel engines showing the results obtained using green fuel additives made of $n$-Butanol, BL and DBE, mixtures which can be directly obtained from the acid-catalysed alcoholysis reaction of lignocellulosic biomasses with a simple conversion process. Their synergic effects on engine performance, combustion characteristics and exhaust emissions have thus been analysed. The obtained results confirm the potentiality of these novel blending mixtures to reduce the emissions of particulate without any significant increasing of $\mathrm{NO}_{\mathrm{x}}$ emission or changing in engine power and efficiency in comparison with conventional Diesel fuel.

\section{Fuel properties and preparation}

The ternary mixture available from one-pot butanolysis of crude i.e. pre-treated biomass is composed by unreacted $\mathrm{n}$ butanol, DBE and BL. All these compounds represent oxygenates diesel additives and their properties have been singularly investigated in blend with Diesel. The properties of all fuel components are shown in Table 1.

Table 1. Overview of biomass resources available from literature $[2,6,8]$

\begin{tabular}{|l|c|c|c|c|}
\hline & BuOH & DBE & BL & Diesel \\
\hline Density $(\mathrm{kg} / \mathrm{l})$ at $25^{\circ} \mathrm{C}$ & 0,81 & 0,77 & 0,97 & 0,84 \\
\hline Boiling point $\left({ }^{\circ} \mathrm{C}\right)$ & 118 & 140 & 232 & $180-360$ \\
\hline Flash Point $\left({ }^{\circ} \mathrm{C}\right)$ & 34 & 25 & 110 & 55 \\
\hline Cetane Number $(\mathrm{CN})$ & 25 & 100 & 14 & 50 \\
\hline LHV (Lower Heating Value) $\mathrm{MJ} / \mathrm{kg}$ & 33,1 & 42,8 & 27,4 & 43 \\
\hline Kinematic viscosity $\left(\mathrm{mm}^{2} / \mathrm{s}\right.$ at $\left.40^{\circ} \mathrm{C}\right)$ & 3,6 & 0,72 & 1,5 & 2,6 \\
\hline
\end{tabular}

The properties reported in Table 1 show that both $n$-butanol and BL have a lower CN than Diesel. This is a common behaviour reported by Koivisto et al. [24] for alcohols and levulinates such as $n$-butanol and BL respectively. These are characterized by higher ignition delays (i.e. lower cetane number) than alkanes of the same carbon atom chain length. However, ethers, such as DBE, have an opposite behaviour and show lower ignition delays in comparison with alkanes. By considering the components of the ternary mixture available from alcoholysis reaction of biomass, DBE plays a fundamental role such as cetane enhancer directly produced during the reactions. This fact enables to test Diesel blended with a high-volume percentage of ternary mixture. In this context, $n$-butanol and BL represent the two components of the mixture which mostly influence the oxygen content in the final blend with diesel.

By considering that the final composition of the reaction can be easily selected, two different tertiary model mixtures 
(mixA and mixB) have been prepared. Moreover, considering the possibility to reutilize the excess alcohol (n-Butanol), a third binary mixture (mixC), made of $\mathrm{Bl}$ and DBE only, was also realised. Their compositions are reported in Table 2.

Table 2. Composition of the prepared mixtures

\begin{tabular}{|l|c|c|c|c|c|c|}
\hline & $\begin{array}{c}\text { BuOH } \\
{[\% \text { mass }]}\end{array}$ & $\begin{array}{c}\text { DBE } \\
{[\% \text { mass }]}\end{array}$ & BL [\%mass] & $\begin{array}{c}\text { density } \\
{[\mathbf{k g} / \mathbf{l}]}\end{array}$ & $\begin{array}{c}\text { LHV } \\
{[\mathbf{M J} / \mathbf{k g}]}\end{array}$ & $\mathbf{C N}$ \\
\hline mixA & 70 & 20 & 10 & 0,82 & 34,47 & 37,10 \\
\hline mixB & 30 & 60 & 10 & 0,80 & 38,35 & 63,50 \\
\hline mixC & 0 & 33,3 & 66,6 & 0,90 & 32,50 & 39,63 \\
\hline
\end{tabular}

A high-gravity approach can be adopted during the reaction, and a $10 \mathrm{wt} \%$ of BL in the final mixture directly produced from biomass can be easily obtained. However, DBE and unreacted n-butanol clearly represents the main components of the final mixtures. Therefore, mixA and mixB presented in Table 2 differ in the relative n-butanol/DBE ratio and have the same content of BL. DBE represents the product of dehydration of n-butanol and its percentage inside the mixture goes up with the increasing of the severity of the reaction while the portion of alcohol decreases. By contrast, weaker reaction conditions lead to a higher ratio n-butanol/DBE.

Preliminary engine tests have been conducted to analyse the influence of blends composition on the Diesel engine performance. Hereafter five blends are presented, which can be considered representative of engine behaviour and whose components can be easily obtained from the alcoholysis reaction. The mixA and mixB have been blended in two different volume percentage with Diesel fuel ( 10 and 20 vol\%), while mixC has been blended at $12 \%$ (still by vol\%). The final five blends, tested in the engine, are summarised in Table 3. It must be underlined that all the mixtures presented a very good stability, without showing any stratification after weeks.

Table 3. Main characteristics of the five blends tested

\begin{tabular}{|l|c|c|c|}
\hline & $\begin{array}{c}\text { density } \\
{[\mathbf{k g} / \mathbf{l}]}\end{array}$ & $\begin{array}{c}\text { LHV } \\
{[\mathbf{M J} / \mathbf{k g}]}\end{array}$ & $\mathbf{C N}$ \\
\hline mixA 10\%vol & 0,84 & 42,1 & 48,7 \\
\hline mixA 20\%vol & 0,83 & 41,3 & 47,4 \\
\hline mixB 10\%vol & 0,83 & 42,5 & 51,4 \\
\hline mixB 20\%vol & 0,83 & 42,1 & 52,7 \\
\hline mixC 12\%vol & 0,85 & 41,7 & 48,8 \\
\hline
\end{tabular}

As aforementioned, it must be highlighted that, in the alcoholysis reaction, the final composition of the mixture can be easily tuned by selecting the reaction parameters correctly and without $\mathrm{BuOH}$ consumption. However, since the scope of the present activity is to verify engine behaviour with the utilization of fuel additive, the mixtures were prepared by using commercial reactants.

\section{Test engine experimental setup}

To test the different blended fuels, a direct injection four-stroke Diesel engine was employed, whose main characteristics are reported in Table 4. The engine has been coupled with a Borghi \& Saveri eddy current brake with rpm/torque controller.

An AVL gravimetric fuel balance was used to online measure the fuel consumption. An Environnement SA test bench, equipped with a Non-Dispersive Infra-Red (NDIR) Sensor, a paramagnetic sensor, a Heated Chemiluminescence Detector (HCLD) and a Heated Flame Ionization Detector (HFID) was employed to measure, respectively, $\mathrm{CO}$ and $\mathrm{CO}_{2}, \mathrm{O}_{2}, \mathrm{NOx}$, and THC (i.e. Total Hydro-Carbons). The particulate matter was determined by means of a dedicated sample line and a AVL smoke meter. An exhaust gas K-type thermocouple was employed to verify the steady state conditions occurrence for each different condition employed as test.

Finally, a Kistler 6052 piezoelectric sensor (sensitivity shift from $150{ }^{\circ} \mathrm{C}$ to $250{ }^{\circ} \mathrm{C}<0.5 \%$ ), combined with a charge amplifier 5011-B, gauged the cylinder pressure. An optical encoder was placed on the frontal side of the crankshaft, while an AVL Indicom system performed data acquisition and processing.

An image of the experimental engine on the test bench is reported in Figure 1. 
Table 4. Experimental engine specifications

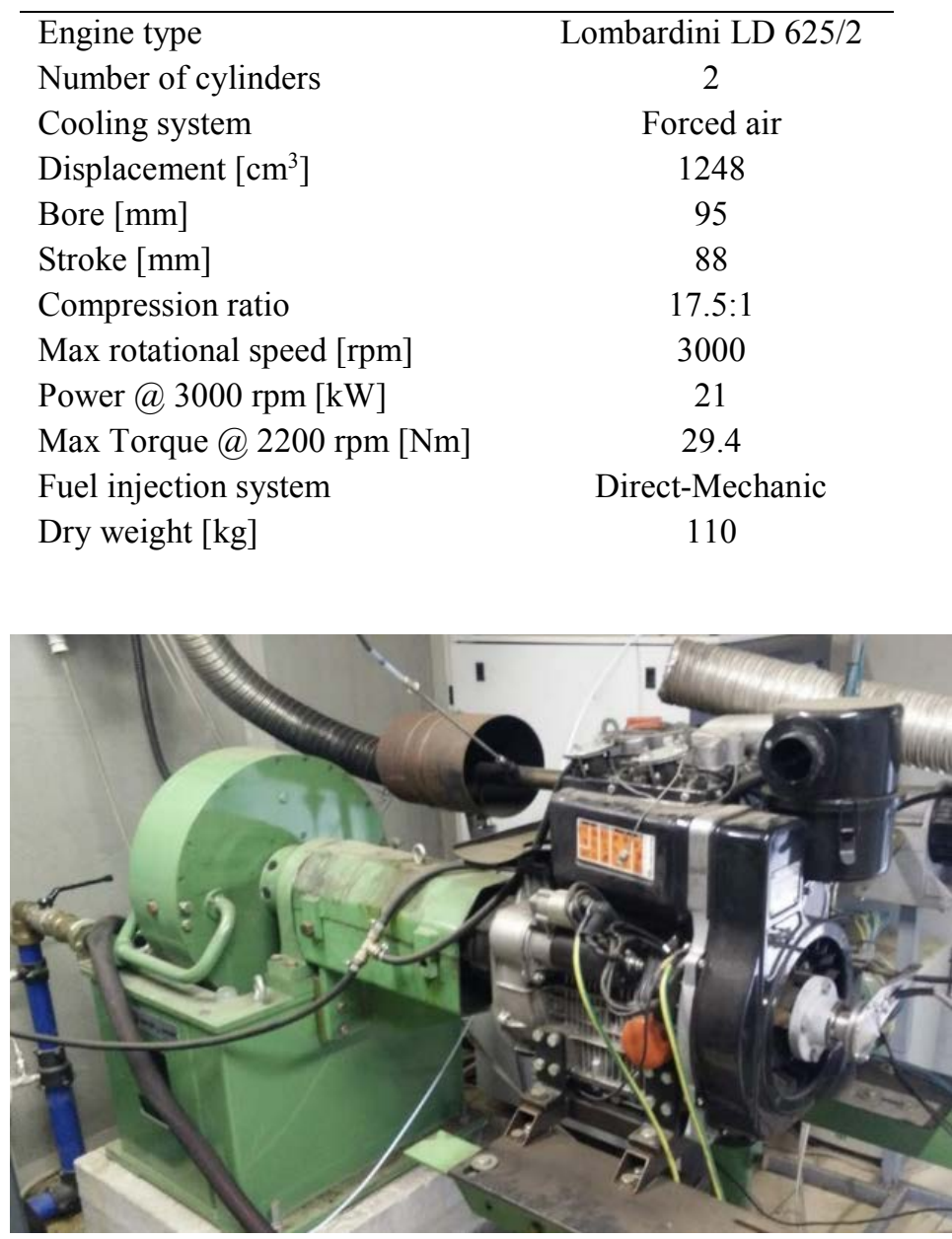

Figure 1. Experimental engine.

\section{Experimental Results}

The engine power at full load as a function of the engine speed is shown in Figure 2. Data are reported for standard Diesel fuel and for the fuel blends. The mixtures employed for the tests resulted in a slightly lower power provided to the test bench. Since the fuel volumetric flow is constant, due to the volumetric mechanical injection system, the lower power can be explained by the reduced LHV of the employed mixtures with respect to the diesel fuel.

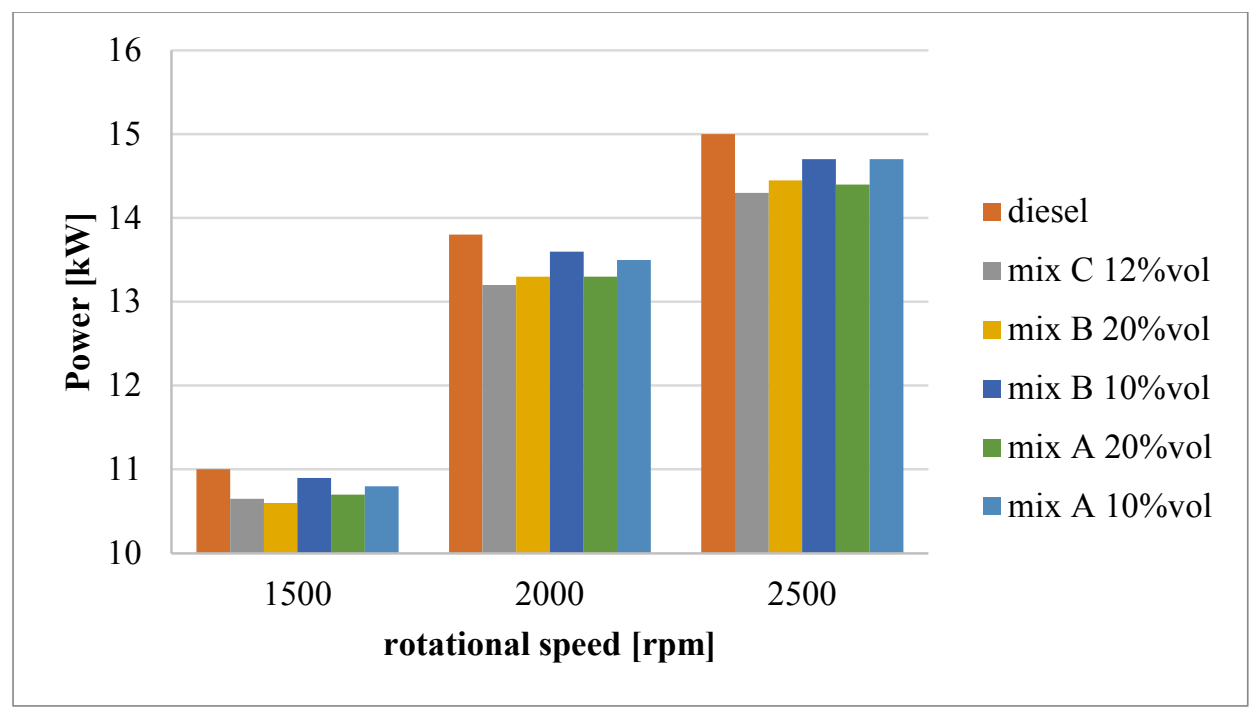

Figure 2. Engine power at full load. 
$\mathrm{HC}$ emissions are in the same order of those obtained utilizing the Diesel fuel only. Also NOx emissions, as displayed in Figure 3, do not show any particular variation in comparison to the utilisation of Diesel fuel, thus indicating that the maximum combustion temperature remained practically unaltered. This is confirmed by the in-cylinder pressure curves obtained utilising the three blends, that do not show any significative variation in comparison with the utilisation of Diesel fuel only, especially at higher rpm, as reported in Figures 4 and 5, which compare, for different rpm, the engine pressure curves obtained utilising mixC $12 \%$ and Diesel fuel alone at full load. However, mixC $12 \%$ showed a little increase of ignition delay, especially at lower speed, due to the reduced $\mathrm{CN}$.

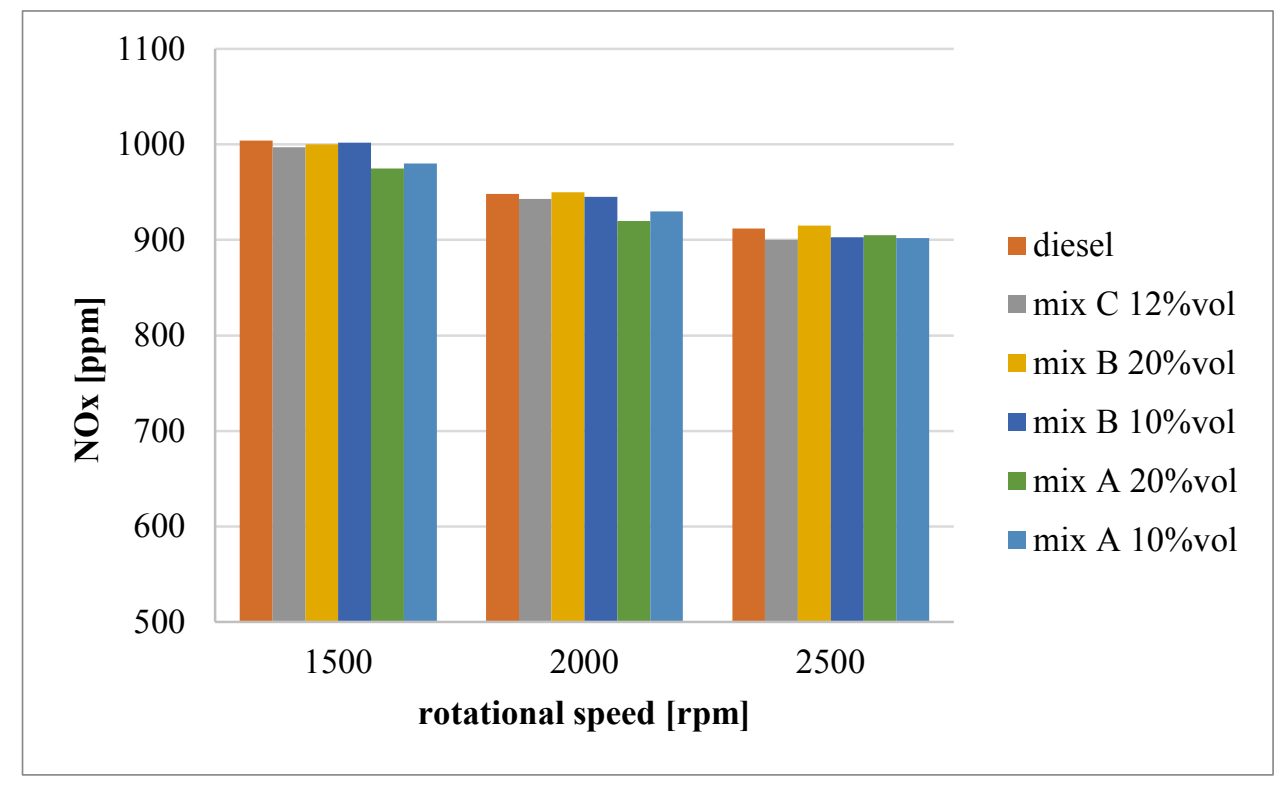

Figure 3. Engine NOx emissions at full load.

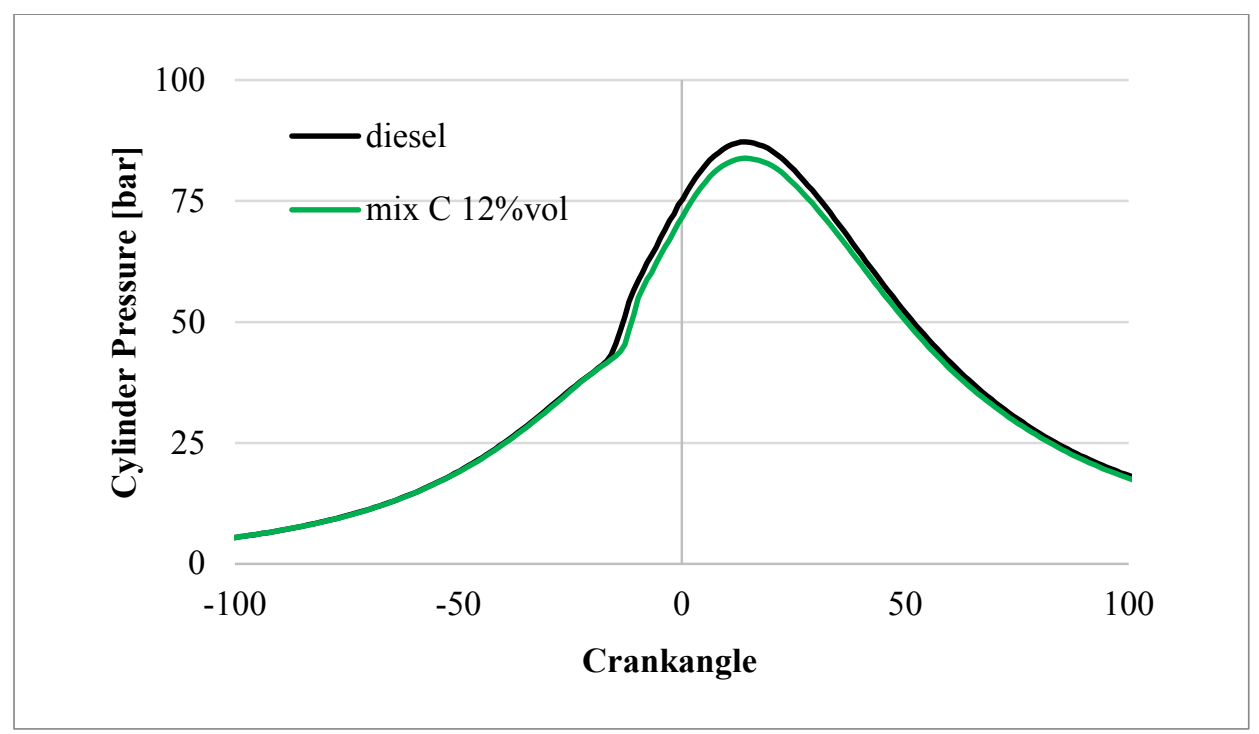

Figure 4. Cylinder pressure at full load and $1500 \mathrm{rpm}$. 


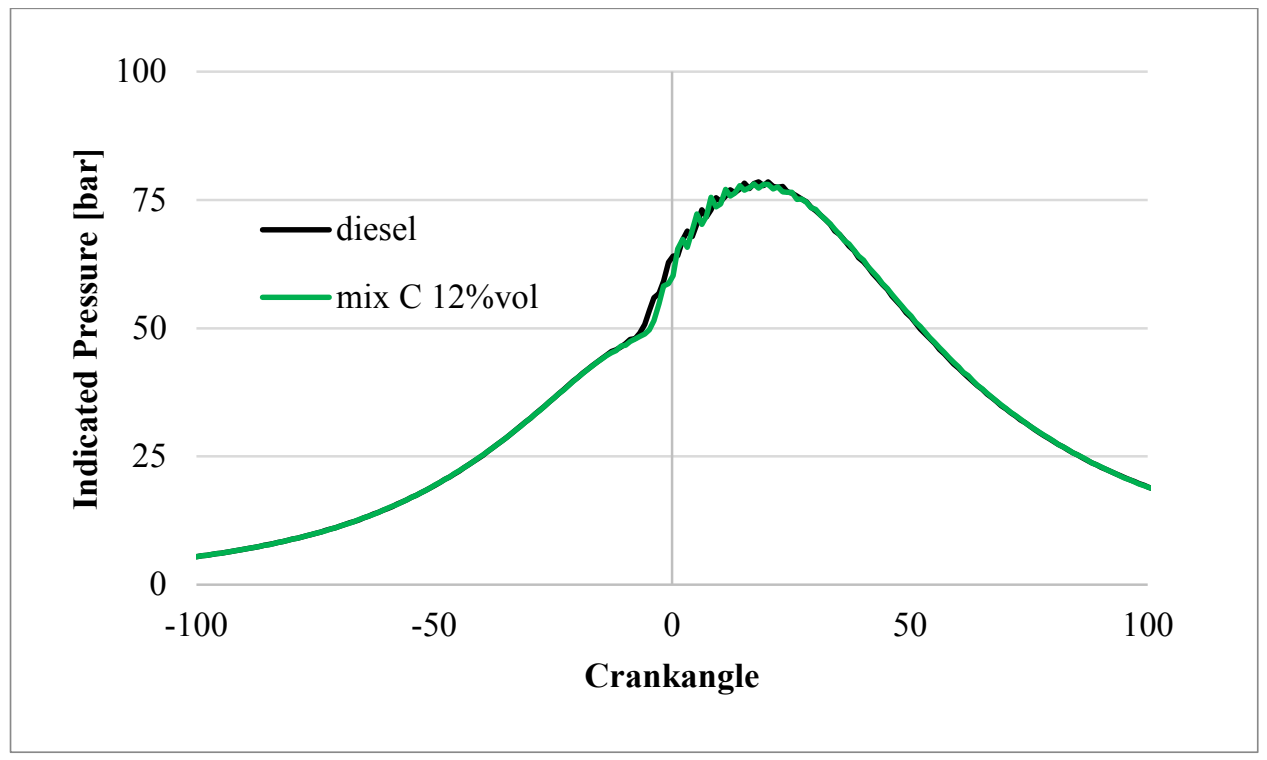

Figure 5. Cylinder pressure at full load and $2500 \mathrm{rpm}$.

$\mathrm{CO}$ emission, reported in Figure 6, shows an interesting reduction for mixB and especially for mixA (blends with higher content of $\mathrm{n}-\mathrm{BuOH})$. On the contrary, mixC $12 \%$ leads to $\mathrm{CO}$ levels similar to diesel fuel. These results suggest the influence of n-Butanol on CO emissions, as evidenced by other authors [9-14]. In fact, the combustion oxygen availability plays a key role in the formation process of the carbon-based pollutants, such as $\mathrm{CO}$ or soot. Particularly, the oxygen provided by the fuel reduces the low air excess zones which is one of the main cause of CO formation. Furthermore, the more oxygen is available from fuel, and the less carbon is present for CO or soot formation.

Regarding the exhaust gas smoke, this was acquired as Filter Smoke Number (FSN) and mass concentration [mg/m³ . As displayed in Figure 7, a significative reduction of the soot emissions was observed. Maximum reduction is around $30 \%$, where a decreasing trend with the increase in mixtures content can be observed. As aforementioned, the lower carbon content of the employed mixtures reduces the carbon availability for soot formation and the oxygen promotes the oxidation processes. This effect was also discussed by Svensson et al. [26] founding that a fuel oxygen content above 27 to $35 \%$ wt could eliminate the soot emission.

Still concerning soot emissions, a physical aspect must also be considered, related to the presence of oxygenated fuels, which is the lower viscosity than Diesel of the mixtures utilized. A low viscosity fuel increases the injectors spraying pulverization. Moreover, the overall lower boiling point of the mixtures increases the mixing capability of the fuel with the air since it leads to a kind of "droplet explosion" once the fuel mixture is introduced in a hot ambient [27, 28], hence increasing the combustion completion of carbon based molecules. As a whole, the mixtures would perform a premixed combustion and the fuel fraction involved in diffusive combustion, responsible for most of the NOx production, was reduced.

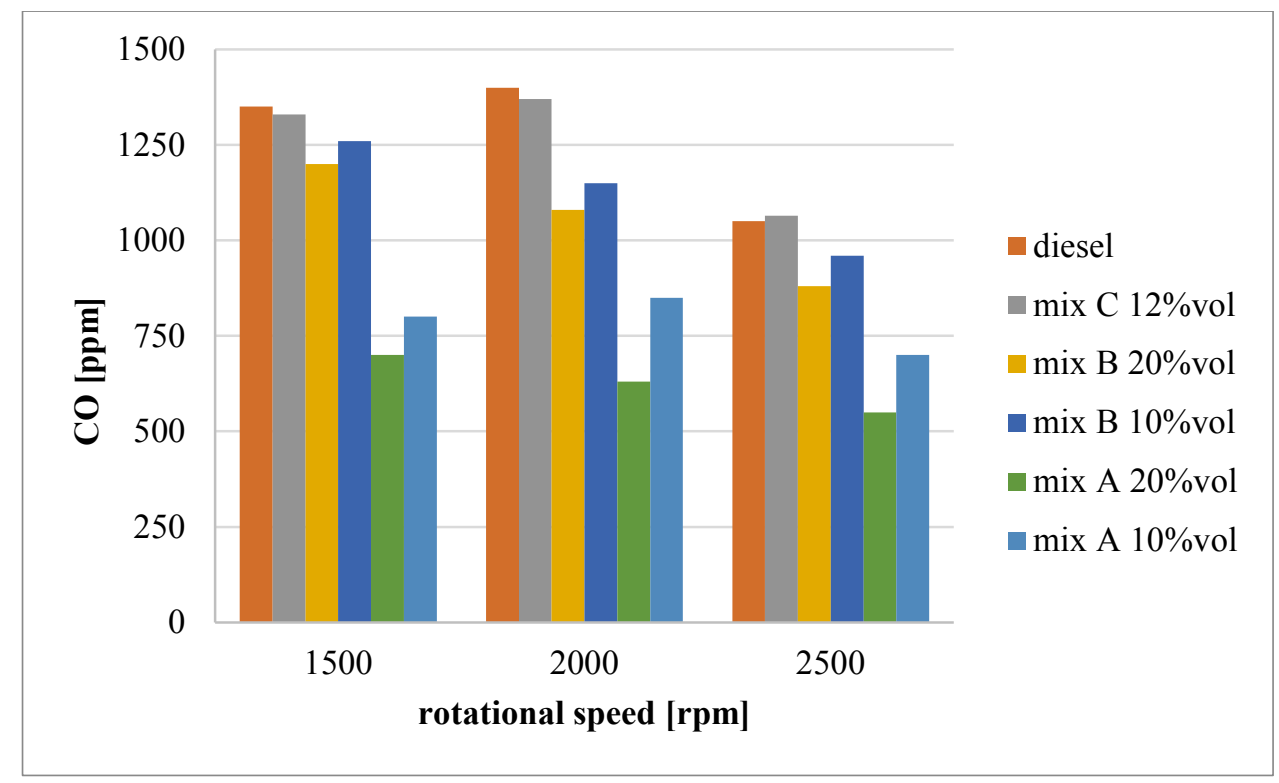

Figure 6. Engine CO emission at full load. 


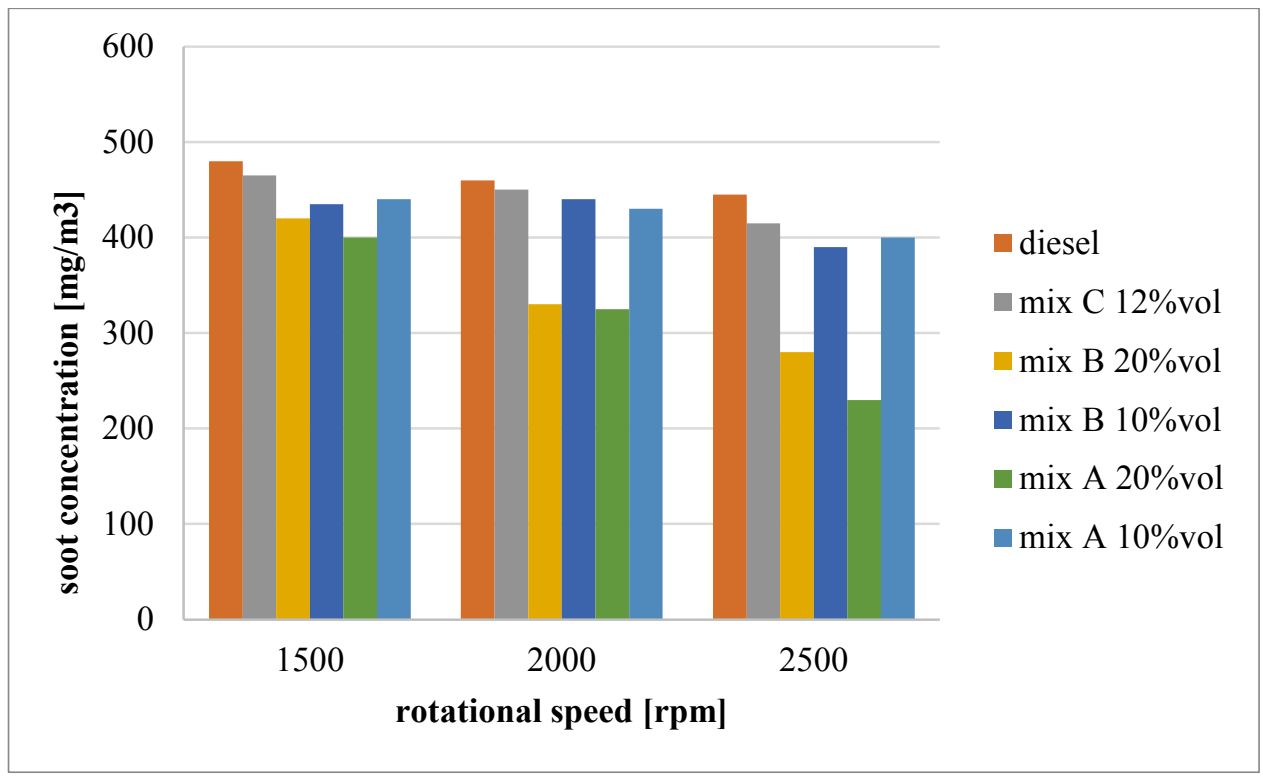

Figure 7. Engine soot emissions at full load.

\section{Conclusions}

The present study shows the result of an experimental activity dedicated to verify the influence, on Diesel engines performance, of innovative fuel mixtures made of conventional Diesel, n-Butanol (n-BuOH), Butyl Levulinate (BL) and n-dibutyl ether (DBE).

$\mathrm{BL}$ and DBE can be obtained from the acid-catalysed alcoholysis reaction of lignocellulosic biomasses utilising nButanol (n-BuOH) as solvent and diluted inorganic acid as homogeneous catalyst. In particular, the BL, which can be directly obtained from the cellulosic fraction of not edible lignocellulosic biomass, represents a promising advanced biofuel and constitutes the effectively renewable component in the different types of blends containing the main products obtainable from the one-pot alcoholysis of lignocellulosic biomasses. On the other hand, the co-produced DBE can improve the properties of the blends due to its high cetane number, even in low percentage, and in this perspective it can be considered a valuable co-product instead of an alcoholysis reaction by-product.

Three fuel mixtures were prepared: two by varying the percentage (by vol.) of the Diesel fuel and n-BuOH/BL/DBE blends, and one utilising only BL and DBE added to Diesel fuel.

The synergic effects of these oxygenated biofuels on engine performance, combustion characteristics and exhaust emissions have been analysed. The obtained results, compared with those obtained fuelling the engine with Diesel fuel alone, confirmed the potentiality of these novel mixtures to reduce the emissions of particulate and $\mathrm{CO}$ without any significant increasing of $\mathrm{HC}$ and $\mathrm{NO}_{\mathrm{x}}$ emission or changing in engine power and efficiency.

In cylinder pressure analysis confirmed the engine performance behaviour, without showing any particular difference among the mixtures tested.

\section{References}

1. C. Antonetti, D. Licursi, S. Frigo, M. Antonelli, M. López, J.C. Parajó, A.M. Raspolli Galletti, “Complete exploitation of eucalyptus nitens: Optimization of hydrothermal conversion of its cellulose fraction to levulinic acid and butyl levulinate", European Biomass Conference and Exhibition Proceedings2019, Pages 1329-133627th European Biomass Conference and Exhibition, EUBCE 2019; Lisbon; Portugal.

2. C. Antonetti, S. Gori, D. Licursi, G. Pasini, S. Frigo, M. López, J.C. Parajó, A.M. Raspolli Galletti, “One-Pot Alcoholysis of the Lignocellulosic Eucalyptus nitens Biomass to n-Butyl Levulinate, a Valuable Additive for Diesel Motor Fuel", Catalysts 2020, 10, 509.

3. M.M. A. Janssen, S. Pischinger, Potential of Cellulose-Derived Biofuels for Soot Free Diesel Combustion, SAE Tech. Pap. (2010) 2010-01-0335.

4. B.H. M. Zubel, S. Pischinger, Assessment of the Full Thermodynamic Potential of C8-Oxygenates for Clean Diesel Combustion, SAE Int. J. Fuels Lubr. (2017).

5. Z.H. Z. Gao, L. Zhu, X. Zou, C. Liu, B. Tian, Soot reduction effects of dibutyl ether (DBE) addition to a biodiesel surrogate in laminar coflow diffusion flames, Proc. Combust. Inst. 37 (2019) 1265-1272. 
6. S.N. Naik, V. V. Goud, P.K. Rout, A.K. Dalai, Production of first and second generation biofuels: A comprehensive review, Renew. Sustain. Energy Rev. 14 (2010) 578-597. doi:10.1016/J.RSER.2009.10.003.

7. R.L.M. E. Christensen, A. Williams, S. Paul, S. Burton, Properties and Performance of Levulinate Esters as Diesel Blend Components, Energy Fuels. 25 (2011) 5422-5428.

8. R.L.M. E. Christensen, J. Yanowitz, M. Ratcliff, Renewable Oxygenate Blending Effects on Gasoline Properties, Energy Fuels. 25 (2011) 4723-4733.

9. D.C. Rakopoulos, C.D. Rakopoulos, E.G. Giakoumis, A.M. Dimaratos, D.C. Kyritsis, Effects of butanol-diesel fuel blends on the performance and emissions of a high-speed di diesel engine, Energy Convers. Manag. 51 (2010) 19891997. doi:10.1016/j.enconman.2010.02.032.

10. A. Atmanli, N. Yilmaz, "A comparative analysis of n-butanol/diesel and 1-pentanol/diesel blends in a compression ignition engine", Fuel 234 (2018), 161-169.

11. M. Nour, Ali M.A. Attia, S. A. Nada, "Combustion, performance and emission analysis of diesel engine fuelled by higher alcohols (butanol, octanol and heptanol)/diesel blends", Energy Conversion and Management 185 (2019), 313-329.

12. A. O. Emiroğlu, "Effect of fuel injection pressure on the characteristics of single cylinder diesel engine powered by butanol-diesel blend", Fuel 256 (2019), 115928.

13. I.M. Yusri, R. Mamat, M.K. Akasyah, M.F. Jamlos, A.F. Yusop, "Evaluation of engine combustion and exhaust emissions characteristics using diesel/butanol blended fuel", Applied Thermal Engineering 156 (2019), 209-219.

14. K.H. Kim, B. Choi, S. Park, E. Kim, D. Chiaramonti, "Emission characteristics of compression ignition (CI) engine using diesel blended with hydrated butanol", Fuel 257 (2019), 116037.

15. H. Kuszewski, "Experimental study of the autoignition properties of n-butanol-diesel fuel blends at various ambient gas temperatures", Fuel 235 (2019) 1316-1326.

16. J. K. Mwangi, W-J. Lee, Y-C Chang, C-Y Chen, L-C Wang, "An overview: Energy saving and pollution reduction by using green fuel blends in diesel engines", Applied Energy 159 (2015), 214-236.

17. Soo-Young No, "Application of biobutanol in advanced CI engines - A review", Fuel 183 (2016), 641-658.

18. B. Rajesh Kumar, S. Saravanan, "Use of higher alcohol biofuels in diesel engines: A review", Renewable and Sustainable Energy Reviews 60 (2016), 84-115.

19. M. Vinod Babu, K. Madhu Murthy, G. Amba Prasad Rao, "Butanol and pentanol: The promising biofuels for CI engines - A review”, Renewable and Sustainable Energy Reviews 78 (2017), 1068-1088.

20. Rust, H., Aron. M., Canada Patent CA2227280 (A1) - 1997-03-06.

21. A. Démolis, N. Essayem, F. Rataboul, "Synthesis and applications of alkyl levulinates", ACS Sustain. Chem. Eng. 2, 1338-1352 (2014).

22. L. Deng, C. Chang, R. An, X. Qi, G. Xu, "Metal sulfates-catalyzed butanolysis of cellulose: butyl levulinate production and optimization", Cellulose 24, 5403-5415 (2017).

23. P. Benito et al., "Tunable copper-hydrotalcite derived mixed oxides for sustainable ethanol condensation to $\mathrm{n}$ butanol in liquid phase", J. Clean. Prod. 209, 1614-1623 (2019).

24. E. Koivisto, N. Ladommatos, M. Gold, The influence of various oxygenated functional groups in carbonyl and ether compounds on compression ignition and exhaust gas emissions, Fuel. 159 (2015) 697-711.

25. A.E. Dodd, Z. Holubecki, "The measurement of Diesel exhaust smoke”, M.I.R.A report, 1965/10.

26. D.R. Tree, K.I. Svensson, "Soot processes in compression ignition engines”, Prog. Energy Combust Sci. 33 (2007), pag. 272-309.

27. D.C.K. Rao, S. Karmakar, S. Basu, "Atomization characteristics and instabilities in the combustion of multicomponent fuel droplets with high volatility differential", Sci Rep 7, 8925 (2017).

28. J. C. Lasheras, A. C. Fernandez-Pello \& F. L. Dryer, "Experimental Observations on the Disruptive Combustion of Free Droplets of Multicomponent Fuels", Combustion Science and Technology,22:5-6,195-209, 1980. 